\title{
Planulation of deep-sea octocorals in the NW Atlantic
}

Received: 6 March 2009/ Accepted: 22 April 2009/Published online: 7 May 2009

(C) Springer-Verlag 2009

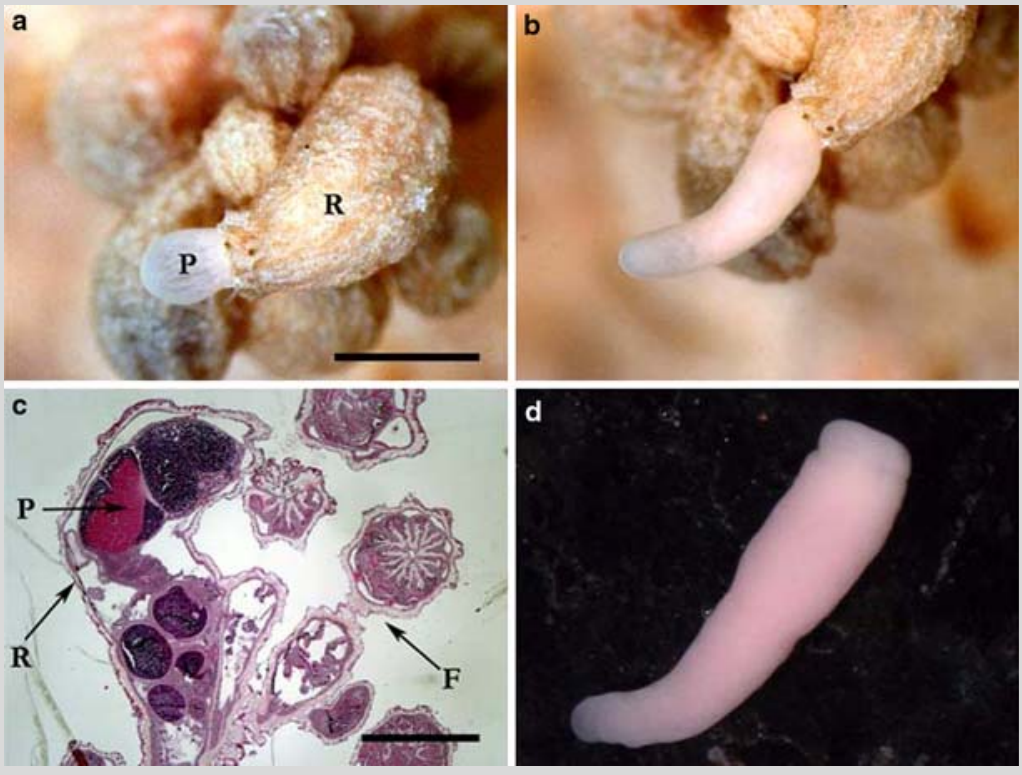

Fig. 1 a-b Planula (P) released through the anterior opening of the specialized reproductive polyp (R) in Drifa sp. c Histological comparison between reproductive (R) and feeding (F) polyps in Drifa sp. d Freshly released planula of D. glomerata. Scale bar: $1 \mathrm{~mm}$. Bar in (a) also applies to (b); bar in (c) also applies to $(\mathbf{d})$

cles; Fig. 1c). In both species, planulae are large (2-6 mm long, possibly the largest ever described) and generally released singly, within $15 \mathrm{~min}$ (Fig. 1a, b, d). Overall, 402 planulae were released by the fertile colonies of Drifa sp. $(n=18)$ and 74 by D. glomerata $(n=1)$.

Acknowledgements This research was partly funded by grants from NSERC and CFI to AM and benefited from logistic and financial support from the Department of Fisheries and Oceans, Canada. Special thanks to E. Edinger, K. Gilkinson, V. Wareham and C. McFadden.

\section{References}

Lumsden S, Hourigan T, Bruckner A, Dorr G (eds) (2007) The state of deep coral ecosystems of the United States. NOAA Technical Memorandum CRCP-3, Silver Spring, MD

Waller R, Tyler P, Gage J (2005) Sexual reproduction in three hermaphroditic deep-sea Caryophyllia species (Anthozoa: Scleractinia) from the NE Atlantic Ocean. Coral Reefs 24:594-602

Z. Sun · A. Mercier ( $₫)$

Ocean Sciences Centre, Memorial University, St. John's, NL A1C 5S7, Canada

e-mail: amercier@mun.ca

J.-F. Hamel

Society for the Exploration and Valuing of the Environment, 21 Phils Hill Road, St. Philips, NL A1M 2B7, Canada
Coral Reefs (2009) 28:781 DOI $10.1007 / \mathrm{s} 00338-009-0505-9$ 